\begin{tabular}{lllllllllllllllllllllllllllllllll}
\hline$R$ & $E$ & $V$ & I & S & T & A & D & E & E & S & T & U & D & I & O & S & I & N & T & E & $R$ & N & A & C & I & O & N & A & L & $E$ & S
\end{tabular}

\title{
Asia del Pacífico ante Estados Unidos: un enfoque heterodoxo
}

\author{
Juan José Ramírez Bonilla
}

Para la mayoría de los analistas internacionales, el 11 de septiembre marca un giro drástico en la evolución del sistema de relaciones internacionales: la "nueva guerra" emprendida por la administración Bush contra el "terrorismo internacional" habría consolidado de manera indiscutible la hegemonía estadounidense. Las intervenciones militares en Afganistán e Irak no contaron con una oposición eficiente de las potencias secundarias y habrían contribuido a la consolidación unipolar del orden internacional.

El presente trabajo ofrece una interpretación diferente: a partir de los acontecimientos cruciales recientes, pretende demostrar que "el orden global" está marcado por una situación contradictoria. Por un lado, el gobierno estadounidense, cierto, es capaz de imponer globalmente sus intereses económicos, políticos y militares, pero esa imposición se realiza a costa de crisis internacionales en los ámbitos en que tales intereses se materializan; por el otro, las crisis internacionales provocadas por el gobierno estadounidense afectan los intereses de las potencias regionales, obligándolas a oponerse a los designios de aquél y a disputarle la influencia política, económica e inclusive militar en sus propios ámbitos geográficos.

A pesar de las acres disputas, ninguna de las potencias nacionales secundarias está en condiciones de desplazar a los estadounidenses. El orden internacional, en consecuencia, evolucionará de crisis en crisis, mientras sigan existiendo las disparidades entre la potencia principal y las potencias secundarias.

espués del 11 de septiembre de 2001, la mayoría de los análisis sobre el sistema de relaciones internacionales se refiere a la fatídica fecha como un parte aguas en la política exterior estadounidense y, dada la función hegemónica de los Estados Unidos, en la historia mundial. El factor determinante del cambio en la evolución del orden global sería la guerra contra el terrorismo internacional, emprendida por la administración Bush y que, en la óptica de la misma, es planetaria por necesidad. Los primeros resultados de esa "nueva guerra" 
parecerían apuntar hacia la consolidación de un orden internacional basado en la hegemonía indiscutible de los Estados Unidos. Al respecto, suele argumentarse que las intervenciones militares en Afganistán e Irak fueron llevadas a cabo de acuerdo con los designios del actual hegemón, sin que ninguna potencia secundaria fuese capaz de presentar una oposición real a los mismos. La conclusión que parece imponerse por sí misma indicaría que la historia posterior al 11 de septiembre reforzó, a la vez, la preeminencia internacional estadounidense y un orden mundial unipolar. Esta conclusión es considerada indiscutible y representa el supuesto básico de los análisis sobre el giro drástico de la historia mundial, luego de los ataques suicidas del 11 de septiembre.

Con el trabajo que el lector tiene ante sí, se desea ofrecer una interpretación diferente de la situación actual. Esta lectura podría ser considerada como heterodoxa, en la medida en que se aleja de los enfoques convencionales en boga y se organiza en torno a la idea siguiente: el fin de la Guerra Fría en modo alguno significó la consolidación de Estados Unidos como la potencia mundial indiscutida de un orden internacional, organizado alrededor de un polo único, predominante en los ámbitos económico, político y militar; antes bien, los acontecimientos determinantes de la evolución del sistema mundial, cuando menos a partir del 2 de julio de 1997, indican que el llamado "orden global" está marcado por una situación contradictoria: por un lado, la supuesta potencia hegemónica no está en condiciones de imponer sus intereses sin provocar crisis internacionales en los ámbitos en que ellos se materializan; por el otro, todavía no existe otra potencia susceptible de desplazar o de disputar a los Estados Unidos su lugar preponderante en el sistema mundial.

\section{Aunque la potencia predominante no puede imponer sus intereses sin provocar crisis internacionales donde ellos se materializan, no hay otra que pueda disputarle su predominio en el sistema mundial.}

Ahora bien, la ausencia de un rival capaz de competir con los Estados Unidos, en pie de igualdad y en todos los órdenes, no significa que otras potencias menores no estén dispuestas a disputarles la influencia en sus propios ámbitos regionales, en las dimensiones política, económica o, inclusive, militar. Dicha ausencia tampoco implica que los gobiernos de los países en desarrollo acepten pasivamente un papel subordinado a la principal potencia mundial; antes bien, algunos de ellos han reaccionado impulsando iniciativas orientadas a preservar sus propios intereses económicos y políticos.

En estas condiciones, las funciones internacionales que el gobierno estadounidense se adjudica a sí mismo son cuestionadas en forma reiterada y este cuestiona-miento genera fricciones con aquellos actores internacional que no están dispuestos a aceptar sin chistar la imposición de intereses ajenos. El presente trabajo, por lo tanto, pretende ilustrar las 
reacciones de los gobiernos de Asia y el Pacífico ante la voluntad del gobierno estadounidense de ejercer un dominio sobre ellos. Las ilustraciones corresponden a cuatro temas cruciales de la historia regional reciente:

- La tentativa de los gobiernos asiáticos de sustraerse, durante la crisis de 1997-1998, al influjo de una economía organizada sobre la base del dólar como medio de pago de las transacciones internacionales y de las instituciones financieras que rigen el sistema económico mundial. Esa tentativa se expresó en los proyectos orientados hacia la creación de instancias regionales, tales como el Fondo Monetario Regional y el Fondo Regional de Estabilización.

- La respuesta de los gobiernos del sudeste asiático a la imposición de los intereses estadounidenses y de las instituciones financieras internacionales durante la crisis asiática, cristalizada en la creación de un foro que agrupa a economías en desarrollo de América Latina y Asia del Este y que pretende defender los intereses propios de los gobiernos asociados.

- Los proyectos de integración regional como respuesta a la crisis de 1997 1998, a la recesión global de 2001-2003 y a las dificultades actuales para reactivar una economía internacional organizada en torno a la estadounidense. Mediante esos proyectos, los gobiernos asiáticos buscan crear mercados regionales, más o menos amplios, donde puedan ejercer, de manera concertada, la regulación de los procesos económicos.

\section{Mediante proyectos de integración regional los gobiernos procuran crear mercados regionales donde puedan regular sus procesos económicos.}

- La actitud de los gobiernos asiáticos ante la guerra contra el terrorismo internacional: a diferencia de instancias como el Consejo de Seguridad de la ONU, la OTAN y la OEA, los gobiernos del Pacífico asiático rehusaron otorgar carta blanca a la administración Bush para llevar a cabo su ofensiva contra la supuesta amenaza terrorista. El distanciamiento de los asiáticos con respecto al gobierno de la potencia "hegemónica" quedó plasmado en las declaraciones de Beijing y de Los Cabos, de los "líderes económicos" de APEC.

\section{LOS PROBLEMAS DE UNA ECONOMÍA GLOBAL ORGANIZADA EN TORNO A LA ESTADOUNIDENSE}

La crisis asiática fue presentada por los analistas anglosajones a partir de los rasgos que, de acuerdo con ellos mismos, marcaban la distinción entre las economías asiáticas y la estadounidense:

- La noción de crony capitalism ponía en evidencia un sistema de relaciones entre agentes públicos y privados que rebasaba los principios del libre mercado e iba en contra de ellos; por esa razón, se argumentaba, las economías asiáticas es- 
tuvieron condenadas a sufrir el colapso de 1997-1998.

- La idea del financial panic introdujo una explicación extraeconómica y monocausal de la crisis, destacando un supuesto grave peligro, latente en cualquier economía cuyos mecanismos no son tan transparentes como aquellos regidos por el libre mercado.

- El diagnóstico relativo a una "crisis de éxito" destacó las virtudes de una administración estricta y disciplinada de las variables macroeconómicas. Sin embargo, paradójicamente, aconsejaba el mismo tipo de reformas estructurales que fue impuesto a gobiernos displicentes como los latinoamericanos.

En síntesis, los principales esquemas interpretativos de la crisis asiática denotaban un doble problema analítico: por un lado, dejaban de lado las peculiaridades del funcionamiento de las economías asiáticas y del desarrollo de las condiciones que hicieron posible la crisis misma, para concentrarse en aspectos que, por contraste, llevaban a "afirmar" de manera apriorística las virtudes del libre mercado; por el otro, se concentraban exclusivamente en la evolución de las variables macroeconómicas y, en consecuencia, no consideraban el rico debate sobre la naturaleza de la crisis y las medidas necesarias para superarla; tampoco tomaban en cuenta los conflictos de intereses, económicos y políticos, que influyeron en la profundización de la crisis económica y en su transformación en crisis política y social. Tal fue el caso de la actitud pasiva de Suharto y de la elite del Nuevo Orden, en Indonesia, ante un programa del Fon- do Monetario Internacional (FMI) que atentaba directamente contra sus intereses; asimismo, fue la situación imperante en Malasia, donde las facciones de Mohamad Mahathir y de Anwar Ibrahim, en el seno de la United Malay National Organization (UMNO), se disputaban el control del gobierno, sin parar mientes en los efectos drásticos de la crisis política en la crisis económica.

\section{Los agentes privados asiáticos} regorganizaron los procesos productivos a partir de una división internacional del trabajo.

Como respuesta a la situación dramática que vivía Malasia, a principios de septiembre de 1998 el gobierno malayo propuso un enfoque analítico diferente y medidas anticrisis "heterodoxas". Indicó que una crisis regional exige medidas de carácter regional, y puso énfasis en la característica distintiva de la crisis: no se trataba de una crisis de economías nacionales aisladas las unas de las otras, sino de la crisis de un complejo económico integrado en una escala regional amplia. Por esa razón, las "reformas estructurales" aconsejadas por el FMI difícilmente podían ser operativas: estaban concebidas para ser aplicadas por gobiernos nacionales en el marco de economías nacionales, cuando lo que se requería eran medidas de carácter regional aplicadas por instancias regionales, cuando no globales.

La integración regional había sido el resultado de la iniciativa de agentes pri- 
vados asiáticos. Estos reorganizaron los procesos productivos sobre la base de una división internacional del trabajo, asignando a cada país de la región asiática del Pacífico un lugar específico en dicha división, de acuerdo con los recursos productivos disponibles. La inversión directa fue, por lo tanto, el factor dinámico de la integración regional, pero, muy pronto la integración se extendió a los ámbitos productivo, comercial e, inclusive, laboral. Los gobiernos actuaron como agentes indirectos del proceso, limitándose a facilitar exportaciones e importaciones de capitales productivos, de bienes y servicios o de mano de obra.

La consolidación del complejo productivo del Pacífico asiático, sobre la base de la intensificación de flujos de capitales canalizados hacia las economías de la región, se llevó a cabo a pesar de dos limitantes importantes: por un lado, la competencia de la economía estadounidense por los recursos financieros disponibles en los mercados internacionales; por el otro, la ausencia de mecanismos intergubernamentales susceptibles de regular el proceso de integración.

\section{LA ECONOMÍA ESTADOUNIDENSE Y LA} COMPETENCIA POR LOS RECURSOS FINANCIEROS

Los analistas del FMI se encargaron de poner en evidencia un fenómeno que pasó inadvertido para la mayor parte de los observadores de los procesos económicos: a principios de los noventa, Japón se había elevado al rango del principal acreedor del mundo; los recursos disponibles por las agencias financieras japonesas eran canalizados, en orden de importancia, a Estados Unidos, Europa y Asia del Pacífico, a tasas de interés extremadamente bajas. La dinámica de la economía estadounidense, hasta entonces, se había apegado al ciclo corto tradicional de expansión/contracción; sin embargo, hacia 1991 dio comienzo a una fase de crecimiento sostenido que se extendió hasta el penúltimo trimestre de 2001. Para mantener el crecimiento, la Reserva Federal aumentó las tasas de interés y, con ello, indujo una reorientación de los flujos internacionales de capital: la economía estadounidense se convirtió en el principal destino de la inversión directa. Es decir, el ahorro externo se convirtió en una de las palancas más importantes para sostener la expansión estadounidense de los noventa.

\section{A principios de los noventa Japón era el principal acreedor del mundo.}

Para las economías asiáticas en desarrollo, en contraste, la industrialización se tornó más onerosa. El aumento de las tasas de interés por parte de la Reserva Federal de los Estados Unidos provocó un encarecimiento generalizado del acceso a recursos financieros frescos, hasta cierto punto limitando la disponibilidad de capitales para llevar el proceso de industrialización a fases superiores, en los países en desarrollo de Asia del Pacífico y de todo el mundo.

El discurso liberal sobre la globali- 
zación contribuyó a velar la naturaleza de este proceso: dado que estaba regido por la operación libre de los mecanismos del mercado, nada se podía objetar al respecto. Sin embargo, en el fondo resultaba ser que, en el afán de alcanzar un interés legítimo desde el punto de vista estadounidense (el crecimiento sostenido), los medios utilizados (el incremento de las tasas de interés) por la Reserva Federal perjudicaron al resto de la economía, fuesen desarrolladas o en vías de desarrollo.

\section{Una decisión unilateral de los} responsables de la principal economía mundial

\section{repercutía en el resto del mundo.}

Aunque en ese momento no era evidente, resultaba que, con el proceso de globalización en marcha, la interdependencia entre las economías nacionales se acentuaba. Por lo tanto, una decisión unilateral de los responsables de la principal economía mundial repercutía necesariamente en el resto del mundo. La estabilidad o la inestabilidad del sistema económico global dependía no del interés general, sino de los objetivos de los responsables de las decisiones económicas del gobierno estadounidense. Por primera vez, la concertación intergubernamental en el ámbito global se hacía sentir cruelmente por su ausencia.

\section{LAS VICISITUDES DE UNA ECONOMÍA REGIONAL ORGANIZADA SOBRE LA BASE DEL DÓLAR}

La crisis asiática mostró de manera palmaria la necesidad de establecer mecanismos intergubernamentales de concertación para administrar tanto la economía regional como las rupturas en la estabilidad económica global. En efecto, durante el período 1985-1997, los gobiernos del Pacífico asiático se abstuvieron de establecer instituciones supranacionales de coordinación intergubernamental. Así, en ausencia de instancias regionales capaces de poner en práctica las medidas requeridas para afrontar la crisis de 1997, y ante la incapacidad de organismos globales, como el FMI, de entender la naturaleza del problema, el gobierno malasio se vio obligado a "aislar la economía nacional", para sustraerla a los efectos negativos de la crisis regional; la paridad fija ringgit/dólar, los controles sobre los capitales de portafolio, la reducción de las tasas de interés internas y la repatriación obligatoria de las inversiones denominadas en ringgits permitieron al gobierno malasio estabilizar y reactivar la economía en un tiempo récord.

Más allá de la oposición entre la supuesta heterodoxia del gobierno malasio y la reconocida ortodoxia del FMI, la crisis asiática mostraba la fragilidad de una economía global organizada sobre la base de un valor convencional tan volátil como el dólar estadounidense. En efecto: 
- El desencadenamiento de la crisis se produjo con la devaluación del baht tailandés. La moneda tailandesa fue sometida, desde el segundo semestre de 1996 hasta el 2 de julio de 1997 a tres embates especulativos. La reserva de divisas del gobierno tailandés estaba denominada en dólares y era inferior a las deudas de corto plazo contraídas en el exterior y, en esas condiciones, los especuladores saquearon las reservas y obligaron al gobierno a devaluar el baht. La crisis cambiaria, sin embargo, pronto adquirió un carácter regional y se transformó en crisis financiera.

- La política monetaria de los gobiernos asiáticos se basaba en el mantenimiento de una paridad fija de cada una de las monedas nacionales con el dólar, lo que implicaba un alineamiento entre las monedas asiáticas, y un cambio brusco en la paridad de una de ellas con respecto al dólar obligaba a una nueva realineación. En consecuencia, la devaluación del baht indujo devaluaciones en cadena, extendiendo la crisis cambiaria a todo el sudeste asiático.

- Las devaluaciones en cadena provocaron la salida precipitada de capitales, acentuando las presiones devaluatorias, pero, sobre todo, creando las condiciones para el desarrollo de una crisis financiera. En efecto, dada la importancia de las deudas de corto plazo contraídas en el exterior por los agentes privados de la mayor parte de los países del sudeste asiático, las devaluaciones elevaron el costo de las deudas, provocando el desplome de los mercados de valores y de bienes raíces. Así, se reunieron las condiciones que provocaron quiebras en cadena.
- La salida de capitales trató de ser contenida con la medida ortodoxa por excelencia: el incremento de las tasas de interés. Este aumento hizo más difíciles las condiciones de supervivencia de los agentes privados, pues sus deudas se encarecían no sólo por las devaluaciones sino también por el aumento de las tasas de interés. La crisis financiera paralizó las economías nacionales.

- La crisis financiera pronto se transformó en una recesión regional que se extendió del sureste al este asiático y que sacudió el sistema económico internacional, empujándolo progresivamente a la recesión global de 2001.

\section{Las políticas anticrisis adoptadas en Malasia marcaron un retroceso en la tendencia a la integración regional.}

En este contexto dramático, tanto las reformas impulsadas por el FMI (en Tailandia, Indonesia, Filipinas y Corea) como las aplicadas por el gobierno malasio se caracterizaron por tener un alcance nacional limitado y por carecer de influencia en los procesos económicos regionales. A pesar de eso, diferían drásticamente: las primeras mantenían las economías sujetas a las influencias de un contexto internacional pernicioso y dificultaban la estabilización; las segundas, en cambio, aislaban a la economía malasia, permitiendo su pronta estabilización y recuperación.

En ese sentido, las políticas anticrisis representaban un retroceso en la tendencia progresiva de la integración regional 
y ratificaban la constatación del gobierno malasio: las autoridades nacionales carecían de medios para influir en las dimensiones regionales de la crisis. Conscientes de esa carencia, los dirigentes políticos empezaron a delinear proyectos de carácter regional:

- Un sistema monetario regional (FMR) que sustrajese las monedas nacionales a la volatilidad de la paridad con el dólar y que permitiese administrar las tasas de interés en el ámbito general del Pacífico asiático.

- Un fondo regional de estabilización constituido mediante aportaciones de los gobiernos con excedentes financieros y manejado al margen de criterios políticos, como los aplicados por el FMI para negar apoyo financiero al gobierno malasio.

Por supuesto, la realización de la iniciativa sobre el FMR hubiera significado la demolición de la arquitectura financiera de la posguerra. Por esa razón, tanto el FMI como el gobierno estadounidense se opusieron a ella, logrando que fuera desechada. Rumiando hiel, los dirigentes asiáticos fueron obligados a replegarse sobre el segundo proyecto $\mathrm{y}$, con una aportación de 20 mil millones de dólares, los japoneses instituyeron el Fondo Miyazawa, destinado a apoyar a los gobiernos de los países en dificultades financieras extremas. Por si eso fuera poco, las autoridades niponas delinearon una nueva propuesta tendiente a facilitar la diversificación de las reservas de divisas, a través del uso del yen como medio de pago de las transacciones comerciales internacionales entre las empresas japonesas y sus contrapartes regionales. Las iniciativas regionales ponían en evidencia que:
- Las economías regional y global no pueden funcionar de manera eficiente regidas únicamente por los mecanismos del libre mercado.

- El dólar estadounidense es una base extremadamente inestable para sostener un sistema económico global cada vez más integrado y complejo.

\section{Se imponía la necesidad de suprimir el desfase entre el carácter regional de la economía y la dimensión nacional de las políticas aplicadas por los gobiernos.}

Los asiáticos, sin capacidad para incidir en las instituciones rectoras del sistema financiero global, optaron por volcarse a la creación y consolidación de instancias regionales. Se imponía la necesidad de suprimir el desfase entre el carácter regional de la economía, en la cual participaban activamente, y la dimensión nacional de las políticas económicas aplicadas por los gobiernos. Para hacerlo, empezaron a diseñar diferentes proyectos de asociación intergubernamental, encaminados a establecer instancias de gestión, bilaterales o multilaterales, para preservar los intereses propios.

\section{LOS PROYECTOS DE ASOCIACIÓN INTERGUBERNAMENTAL}

Desde principios de los años noventa, los países agrupados en la Association of South East Asia Nations (ASEAN) 
adoptaron una actitud defensiva respecto de las decisiones de los países pertenecientes a la entonces Comunidad Económica Europea de encaminarse hacia la constitución de la Unión Europea actual y de los gobiernos de América del Norte de establecer un area de libre comercio subcontinental.

En un primer momento, el gobierno malasio, con el apoyo tácito de sus socios de la ASEAN, propuso la creación de un bloque asiático denominado East Asian Economic Grouping (EAEG), formado por los países que entonces eran considerados de industrialización reciente (Corea, Taiwán, Hong Kong y Singapur), por el grupo conocido como ASEAN-4 (Malasia, Tailandia, Indonesia y Filipinas) y por Japón. Ante la censura del gobierno de Bush padre, el gobierno nipón se rehusó a encabezar un proyecto susceptible de envenenar las relaciones con sus socios estadounidenses y mató en el huevo el primer proyecto de asociación intergubernamental regional que anteponía los intereses propios a los de los países desarrollados de América del Norte y de Europa.

Ante la imposibilidad de construir un proyecto amplio de asociación regional, los gobiernos de la ASEAN se vieron obligados a replegarse sobre sí mismos, sentando las bases del ASEAN Free Trade Area (AFTA), un área de libre comercio integrada por economías en desarrollo, como medio de reducir los riesgos inherentes a la creación de bloques económicos cerrados, en América del Norte y en Europa. El proyecto original del AFTA se limitaba a reducir las tarifas arancela- rias de los productos manufacturados a un rango del 0 al $5 \%$; el rápido progreso del TLCAN y de la UE, en vísperas de la crisis asiática, apresuró la reducción de los aranceles y se hizo extensiva a los productos agropecuarios. Nótese, sin embargo, que se trataba de un mecanismo de libre comercio simple y que dicho mecanismo fue insuficiente para hacer frente a las dificultades generadas por la crisis de 1997-1998, que fue la primera acción concertada de gobiernos de países en desarrollo para defender sus propios intereses ante los gobiernos de los países desarrollados, pertenecientes o no a la región del Pacífico asiático.

\section{Japón rechazó el primer proyecto de asociación intergubernamental regional que anteponía los intereses propios a aquellos de los países desarrollados.}

Durante la crisis de 1997-1998 y luego de la negativa de la administración Clinton y del FMI de aceptar la creación del Fondo Monetario Regional, el gobierno de Singapur formuló una nueva iniciativa: la creación de un foro propio de los países en desarrollo de la región del Pacífico, para identificar y defender sus intereses comunes. Por supuesto, quedaba implícito que era de los Estados Unidos y de las instituciones financieras internacionales de quien había que defenderse.

Del lado americano del Pacífico, el gobierno chileno fue el primero en hacer suya la iniciativa de su similar singa- 
purense. Entre ambos, impulsaron la creación del Foro América Latina-Asia del Este (FALAE). Los gobiernos de Japón, Australia y Nueva Zelandia (considerados como países desarrollados) se sumaron al proyecto, sin desvirtuar su naturaleza.

\section{La fase actual de la evolución de la economía mundial está marcada por el predominio de los grandes bloques regionales.}

Con FALAE se buscaba volver al espíritu original del APEC: establecer un foro de consulta, laxo, que funcionara sobre la base del consenso y sin establecer obligaciones para los gobiernos participantes. Su objetivo principal era promover el acercamiento de los gobiernos latinoamericanos y asiáticos, a partir de criterios geográficos nuevos: abarca dos regiones amplias y, por lo tanto, es la primera iniciativa destinada a consolidar una organización multilateral interregional.

Hasta ahora, 27 gobiernos pertenecen al foro, que cambió su denominación de origen por la del Foro de Cooperación América Latina-Asia del Este (FOCALAE). De ellos, 12 son latinoamericanos, 13 asiáticos y 2 de Oceanía. Como se ha señalado, 3 países considerados como desarrollados se sumaron al foro. Sin embargo, debe tenerse en cuenta las peculiaridades de estos, pues Japón, que es una potencia económica mundial, tiene influencia política y militar, más que nada regional; por su parte, Australia y Nueva
Zelandia tienen apreciable influencia regional y por lo tanto, sus gobiernos, como socios de diálogo, son más accesibles que el de la pretendida potencia hegemónica.

Desafortunadamente, FOCALAE no ha colmado las expectativas generadas luego de su creación. En buena parte, ello se debe a la incomprensión por parte de la mayoría de los actores políticos, de la fase actual del desarrollo de la economía mundial. Se trata de una fase marcada por el predominio de los grandes bloques regionales y por la pérdida de relevancia de las dimensiones nacionales de los procesos económicos, políticos y sociales La consecuencia de esa incomprensión es una actitud política que privilegia esas dimensiones nacionales sobre las regionales y las mundiales.

A pesar de ello, FOCALAE, además de ser una organización multilateral interregional, es un foro cuya masa crítica está constituida por países en desarrollo de ambas regiones circundantes del Pacífico. Como tal, podría funcionar como medio de concertación para actuar en otras organizaciones en las que la principal potencia mundial ejerce una influencia prácticamente incontrovertida. En todo caso, el foro ha sido una experiencia interesante, que muestra a gobiernos de países en desarrollo en la búsqueda de mecanismos para contrarrestar la influencia de la gran potencia mundial.

\section{LA RECESIÓN MUNDIAL DE 2001}

Al comenzar el siglo XXI, las economías asiáticas del Pacífico ya habían vuelto a registrar tasas positivas de crecimien- 
to real, pese a lo cual su ritmo de crecimiento se mantuvo por debajo del alcanzado durante la fase expansiva de 19851997. Por necesidad, ese crecimiento relativamente lento afectó, en forma negativa, la evolución del comercio mundial. Entre los sectores más afectados destacaban las ramas de la informática y de la electrónica que permitieron el "milagro" asiático y el crecimiento sostenido de la economía estadounidense en los años noventa. Por supuesto, los sectores industriales conexos también se vieron afectados, extendiendo la morosidad a toda la economía estadounidense.

En el lado asiático del Pacífico, los problemas que afectaron a la economía estadounidense pusieron en entredicho la reactivación. Con todo, y dado que el mercado regional había logrado captar parte importante del comercio exterior de las economías asiáticas, Estados Unidos seguía y sigue siendo un destino importante de las exportaciones de bienes manufacturados. Las dificultades con que tropezaba los Estados Unidos implicaron, en consecuencia, una disminución de las importaciones de origen asiático la que, por su parte, provocó una nueva reducción del ritmo de crecimiento de las economías asiáticas, que se especializa en los sectores de la informática y la electrónica.

Gracias a los nexos de interdependencia, la morosidad estadounidense indujo una morosidad asiática. Así, durante los tres primeros trimestres de 2001, los analistas de ambas riberas del Pacífico esperaron con impaciencia la publicación de los indicadores del comportamiento económico estadounidense, con la espe- ranza de que apuntaran hacia una reactivación que permitiese volver a dinamizar la economía mundial.

\section{Los nexos de interdependencia hicieron que la morosidad estadounidense provocara una morosidad asiática.}

Los atentados suicidas del 11 de septiembre tuvieron como telón de fondo esa morosidad global. Pero los ataques contra el World Trade Center de Nueva York fueron catastróficos para las empresas del transporte aéreo y del turismo internacional. Como se recordará, las aerolíneas debieron ser subsidiadas por el gobierno estadounidense y sometidas a una profunda reestructuración de costos de operación. La catástrofe se extendió y la economía estadounidense entró en franca recesión durante el cuarto trimestre del año.

De nueva cuenta, se impuso la lógica de la interdependencia propia de la globalización: la recesión en el epicentro de la economía global indujo una recesión generalizada. Asímismo, volvió a imponerse una conclusión evidente: una economía global organizada en torno a Estados Unidos implica, para el resto del mundo, seguir inercialmente la tendencia marcada por el epicentro del sistema.

Los hechos, por otra parte, confirmaron el diagnóstico de los asiáticos: ante las dificultades derivadas del predominio de una economía en el ámbito mundial y de la operación de los mecanismos de libre mercado, no queda sino una alternativa: 
- Empeñarse en fortalecer el mercado nacional, aislándolo de los efectos perniciosos de un ambiente internacional deprimido. El programa anticrisis aplicado por el gobierno malasio a partir de los primeros días de septiembre de 1998 ilustra esta opción, la cual, no obstante, representa un retroceso en la consolidación tanto de la economía regional como de la global. En la misma dirección apunta la declaración de Vicente Fox, formulada con dos años de retraso, el $1^{\circ}$ de septiembre de 2003, acerca de la necesidad de fortalecer el mercado interno.

\section{La recesión en el epicentro de la economía global indujo una recesión generalizada.}

- Participar en un proceso de integración regional amplio, pero dotado de mecanismos que permitan limitar la influencia perniciosa de los problemas propios de los Estados Unidos. En ese sentido, los gobiernos del Pacífico asiático han explorado y empezado a poner en práctica acuerdos intergubernamentales que les permitan administrar los procesos económicos en el ámbito supranacional. Entre tales acuerdos destacan: los bilaterales para asociaciones económicas; el proyecto multilateral de asociación económica ASEAN+3, es decir los diez países miembros de la Asociación de Naciones del Sud Este de Asia más Japón, China y Corea del Sur; la propuesta de un Mercado Único de ASEAN, dotado, en el 2020, de una moneda única.

Para los asiáticos, la puesta en prácti- ca de los acuerdos de asociación económica permite potenciar los mercados nacionales, pero, sobre todo, permite crear un mercado regional amplio, susceptible de limitar el impacto de desequilibrios existentes en otros segmentos del mercado mundial. Con esta opción, los asiáticos han desechado por completo el cliché de un orden económico mundial unipolar y apuestan a convertirse en participantes activos de un orden organizado sobre la base de una tríada regional: América del Norte/Asia Pacífico/Unión Europea.

\section{EL COMBATE CONTRA EL TERRORISMO}

INTERNACIONAL Y LA COMPETENCIA POR LA INFLUENCIA POLÍTICA

Luego de la intervención estadounidense en Irak, buena parte de los observadores internacionales concluye que ella representa la confirmación de la hegemonía política y militar estadounidense, pues nadie, dentro o fuera del marco de las Naciones Unidas, fue capaz de impedir que la administración Bush pusiera en práctica sus designios. La conclusión tiene validez, siempre y cuando se la sustente únicamente en los resultados de la intervención.

Por el contrario, si se pone atención en el proceso de negociaciones que subyace la intervención, la conclusión es radicalmente diferente: la decisión unilateral de la administración Bush de invadir Irak puso en crisis el sistema multilateral de las Naciones Unidas. Por su parte, la crisis sacó a la luz una disputa 
entre el gobierno estadounidense y sus similares de otras potencias de segundo orden, por la influencia política. Ahora bien, la disputa estuvo marcada por la relación de fuerzas prevaleciente en el ámbito mundial: el gobierno estadounidense no está en condiciones de imponer sus intereses sobre las potencias secundarias, pero ninguna de éstas puede disputarle la hegemonía política global. La disputa por la influencia política, en consecuencia, quedó reducida al ámbito regional de las potencias desafiantes; en ese sentido, el gobierno estadounidense domina la escena internacional, pero no predomina sobre sus contrapartes alemana, china, francesa y rusa, pues éstas buscan consolidar sus propias áreas de influencia política, reduciendo la pretendida hegemonía absoluta estadounidense a una dimensión relativa.

En el Pacífico asiático, la actitud de los gobiernos chino y ruso sólo puede ser entendida si se tiene en cuenta el marco general de la "lucha contra el terrorismo internacional". El lector recordará que, después de los ataques suicidas del 11 de septiembre, la administración Bush adoptó la noción de guerra preventiva como recurso para acabar con las amenazas contra la seguridad de los Estados Unidos. El Consejo de Seguridad de las Naciones Unidas, primero, y, posteriormente, la OTAN y la OEA legitimaron dicha noción, otorgando carta blanca al gobierno de Bush para intervenir militarmente dónde y cuándo percibiese una amenaza para la seguridad estadounidense.

La intervención en Afganistán, a finales de 2001, contó con un respaldo amplio de la "comunidad internacional". Sin embargo, en el caso de Irak, los pretextos para justificar la intervención empezaron a deslizarse: del combate contra un gobierno que albergaba y financiaba grupos terroristas se pasó a la necesidad de liquidar las armas de destrucción masiva supuestamente detentadas por el gobierno iraquí, primero, y, luego, a la obligación de derrocar un gobierno reconocido por todas las instituciones multilaterales. Los gobiernos de las potencias secundarias se dieron cuenta de que, con las resoluciones del Consejo de Seguridad, de la OTAN y de la OEA, habían creado un Frankenstein, capaz de atentar contra cualquier gobierno reconocido.

\section{La crisis puso de manifiesto una disputa por la influencia política entre el gobierno estadounidense $\mathbf{y}$ sus similares de potencias de segundo orden.}

Entre estos yerros político-jurídicos y rectificaciones de actitud, cabe destacar que, en Asia del Pacífico, los gobiernos fueron mucho más cautos y se negaron a otorgar carta blanca a la administración Bush para combatir el "terrorismo internacional". En efecto, en la reunión de Beijing, de octubre de 2001, los "líderes económicos del APEC" (eufemismo utilizado en ese foro para designar la cumbre de jefes de gobierno) se solidarizaron moralmente con el gobierno estadounidense, pero indicaron que la lucha contra el terrorismo debía llevarse a cabo 
dentro del marco de las Naciones Unidas. Posteriormente, en la reunión de Los Cabos, de octubre de 2002, ratificaron a las Naciones Unidas como el marco propicio para combatir las amenazas terroristas.

\section{Los líderes económicos \\ mostraron cautela ante la posibilidad de que el gobierno estadounidense pudiera invervenir militarmente un país a pretexto de combatir el terrorismo.}

La posibilidad de que el gobierno estadounidense interviniese militarmente en cualquier país bajo pretexto de combatir el terrorismo, es la principal explicación de la cautela de los "líderes económicos". En efecto, el APEC es un foro integrado por 20 "economías": cinco están localizadas en el continente americano, dos en Oceanía y trece en la región asiática del Pacífico. De estas trece, en Brunei, China, Filipinas, Indonesia, Malasia, Rusia, Singapur y Tailandia, el Islam es una dimensión social de mayor o menor grado de presencia, pero de incuestionable importancia política. La identificación superficial entre Islam y terrorismo tornaba a esos países como blancos potenciales de la campaña antiterrorista de Bush.

Además, a mediados de 2000, los gobiernos de China, Rusia, Uzbekistán, Tadjikistán y Turkmenistán crearon el Club de Shanghai, con el fin de coordinar las actividades para contener las corrientes políticas islamistas, presentes en los territorios respectivos, pero con gran movilidad entre los mismos. Esos gobiernos se consideraban, por lo tanto, autosuficientes para combatir a sus propios militantes islamistas y no querían nada con la campaña de Bush.

En el sudeste asiático, la situación era diferente: el malestar social generado por la crisis de 1997-1998 provocó una efervescencia política que tendía a cuestionar el desempeño de los gobiernos nacionales. La apertura de espacios de participación política permitió a algunas corrientes islamistas desarrollarse en países como Indonesia, Malasia, Singapur y Tailandia; en otros como Filipinas, y aun Indonesia, se acentuaron viejos conflictos que oponían a facciones islamistas con los gobiernos centrales. El clima generado por la campaña antiterrorista estadounidense sirvió de marco para emprender campañas internas que, de paso, sirvieron para ajustar cuentas con los opositores políticos.

Lejos de suprimir las corrientes islamistas radicales, la represión ha tenido como resultado inmediato la agudización de las tensiones sociales en todos los países que tienen población musulmana y el incremento del terrorismo en Filipinas e Indonesia (aunque cabe señalar que, en el último caso, quedan dudas sobre el origen real de los autores intelectuales de los atentados más sangrientos).

En Asia del Pacífico, la campaña antiterrorista de Bush ha encontrado dos tipos de oposición: en los casos de China y Rusia, los gobiernos buscan sustraerse al predominio del gobierno estadounidense y, de paso, fortalecer su influencia política en sus propios ámbitos regionales. En los casos restantes, se trata de evitar 
el dominio militar estadounidense en espacios considerados de la incumbencia exclusiva de los gobiernos nacionales.

La hegemonía política estadounidense quedó resquebrajada luego de la experiencia traumática de la intervención militar en Irak. En consecuencia, en el ámbito geográfico empieza de configurarse un nuevo orden político basado en la influencia regional de potencias secundarias. Esta recomposición regional, por supuesto, tiende a traslaparse con la tríada regional fundada sobre premisas económicas.

\section{Conclusiones}

A principios de los años noventa, el orden internacional entró en una nueva fase: con la disposición de los gobiernos asociados en la Comunidad Económica Europea de poner en práctica el proyecto del mercado único europeo, con la voluntad de los gobiernos de Canadá, Estados Unidos y México de negociar un acuerdo de libre comercio y con el proceso de integración económica promovido por las empresas asiáticas, los bloques regionales desplazaron a las economías nacionales como los principales componentes de la economía mundial. Es decir, ésta dejó de estar integrada por economías nacionales.

El camino seguido por los europeos para transitar del mercado único a la Unión Europea parecería indicar la senda obligada para aquellos países cuyo peso específico es secundario, deseosos de figurar en la escena mundial y de sustraerse al predominio de la potencia hegemónica de la post Guerra Fría. Tal es el caso de los países asiáticos del Pacífico, pues sus gobiernos se encuentran comprometidos en un sinnúmero de proyectos de integración económica, entre los que cabe destacar los dos siguientes:

\section{Empieza a configurarse un orden político basado en la influencia regional de potencias secundarias.}

- $A S E A N+3$, por su extensión geográfica y por las potencialidades que representan cerca de 2 mil millones de personas.

- $A S E A N$, por la rapidez con que han decidido profundizar los vínculos económicos para conformar un mercado único, dotado de una moneda única, en el 2020.

Por si eso fuera poco, los problemas extraeconómicos regionales empiezan a influir en el rumbo de la integración: la piratería marítima, el tráfico de personas y de drogas, el comercio ilegal de armas, el lavado de dinero, el terrorismo, los problemas ambientales, por sólo citar algunos de los problemas más relevantes, no pueden ser resueltos mediante acciones en las que participan únicamente las ramas ejecutivas de los gobiernos en que, por el contrario, su solución exige la acción coordinada de las ramas legislativa y judicial. En algunos casos, ya se han producido las primeras acciones y, con toda probabilidad, estas serán cada vez más frecuentes, extendiendo el proceso de integración de la esfera económica a la política.

El orden mundial, hoy más que nunca parece progresar hacia la consolidación 
de los bloques regionales y hacia una erosión de la importancia de los Estados Unidos. Mientras más avance el proceso de integración económica y política, el bloque del Pacífico asiático tendrá mayores posibilidades de substraerse a la influencia militar estadounidense.
Con respecto a los gobiernos de América Latina, la pregunta en el aire se refiere al tiempo que habrán de tardar en cobrar conciencia de que una integración regional profunda puede ser el mejor medio para redefinir sus relaciones con la principal potencia mundial. 